\title{
Las biografías y la historia de la etnología*
}

\section{INTRODUCCIÓN}

El tema de este trabajo es el empleo de la biografía científica en la historia de una disciplina concreta, la antropología, circunscrita a nuestro propio país. Con la idea de intentar un acercamiento amplio que inscriba la biografía como un enfoque metodológico útil para varias ciencias humanas y sociales, cercanas e interrelacionadas, se presenta, en primer lugar, un esbozo de la situación de tal uso en la historia, la sociología, la etnología y la historia de las ciencias. Para el caso concreto de la etnología se analiza el interés existente en la actualidad hacia las circunstancias particulares de la participación del observador en la cultura que estudia y sus consecuencias teóricas e historiográficas. Tras estas cuestiones, tratadas de forma introductoria, se abordarán ya los elementos más concretos referidos a los tipos de aplicación de la biografía en la historia de la etnología y a aspectos metodológicos en la confección de biografías científicas. Finalmente, estos problemas se trasladan al caso de la investigación sobre historia de la antropología en España, insistiendo en la validez de una aplicación correcta del enfoque biográfico a ciertos temas y problemas de orden general.

\section{LA BIOGRAFÍA EN LA HISTORIA, LA SOCIOLOGÍA Y LA ETNOGRAFÍA}

Las biografías se consideran comúnmente como un género literario, cuya popularidad se ha mantenido constante en casi todas las épocas, bien fuera por la vertiente de ofrecer una imagen «típica» o «arquetípica» de hombres buenos (o malos) - vidas ejemplares - con una intención pedagógica y moralizante indudable, bien a través de la exalta-

\footnotetext{
* Este trabajo fue presentado como ponencia en el simposio Historia de la Antropologia: Personas, miradas y tradiciones, dirigido por el Dr. D. Fermín del Pino Díaz, dentro del $V$ Congreso de Antropología, celebrado en Granada entre el 10 y el 14 de diciembre de 1990. No se han introducido modificaciones sustanciales en el texto presentado al Congreso, ni se ha actualizado la bibliografía. Agradezco a los organizadores del Congreso la posibilidad de su publicación independiente, y, muy particularmente, a Fermín del Pino por su amable invitación a ser ponente en su simposio y por la cuidadosa revisión del texto original; sus numerosas sugerencias y propuestas han contribuido sin duda, a mejorarlo.
} 
ción de figuras extrañas o marginales, lejos de la norma, que llamaban la atención del público, o de ciertos sectores del mismo '.

La biografía es también un método de conocimiento histórico de gran raigambre; los documentos personales, memorias, etc., han sido siempre una apreciada fuente usada por los historiadores. La historia tradicional en gran parte era biográfica, aunque se centrara con exclusividad en la vida de determinado tipo de personajes (reyes, guerreros, políticos) y la narrara de cierta forma precisa, en consonancia con una idea personalista o individualista del proceso histórico y casi únicamente centrada en el aspecto político. La aplicación de tipos de análisis más rigurosos y sistemáticos en la historiografía hizo que, durante un tiempo, el recurso a la biografía fuera visto por muchos historiadores como falto de rigor y cientifismo. Tal crítica tenía su origen, en primer lugar, en la forma en que muchas biografías estaban hechas, sustentadas más en el mito y la anécdota que en un conocimiento que pudiera calificarse como científico. Pero, sobre todo, era la concepción de la historia como una genealogía de héroes y grandes hombres lo que se consideraba periclitado. La renovación teórica y metodológica se alejaba de las explicaciones particularistas e individualistas, en busca de leyes del comportamiento histórico apoyadas en realidades sociales y económicas, lo cual no armonizaba con el registro personalizado de los relatos de vidas.

Sin embargo, también dentro de la nueva historiografía se produjo, frente al empleo abusivo de las técnicas cuantitativas, un cierto giro hacia la historia individual, claro es que empleando una clase de personajes, argumentos, hipótesis y métodos de investigación poco coincidentes con los de la biografía tradicional '. La historia oral, la historia de las mentalidades, de la vida cotidiana, pueden encontrar un registro privilegiado en las vidas particulares. Aparte de que, junto a otras tendencias, pueda seguir considerándose la actuación de figuras destacadas como móvil de la historia, aunque, como es lógico, sin excluir otras causas. Por tanto, fueron los historiadores quienes primero recurrieron a documentos personales y los que antes desarrollaron criterios y técnicas de crítica y verificación en el uso del método biográfico ?.

Julio CARO BAROJA, «Género biográfico y conocimiento antropológico», Biografías y' ridas humanas (San Sebastián: Txertoa, 1986), pp. 8-37.

Carlo Ginzburg, El queso y los gusanos. El cosmos, según un molinero del siglo Xil (Barcelond: Muchnik, 1981), pp. 13-28. .

Juan F. MARSAl, "Historias de vida y ciencias sociales», J. BALÁn (ed.), Las historias de vida en ciencias sociales. Teoria y técnica (Buenos Aires: Nueva Visión, 1974), p. 43; Louis GotTschalk et al., The Use of Personal Documents in History, Anthropology and Sociology (New York: Social Science Research Council, 1945). 
Dejando a un lado la utilización en otras disciplinas, como la psicología, la tradición de las «historias de vida» en sociología es también larga, hasta el punto de que, según algunos sociólogos que defienden su uso, se trataría de un «método» inventado por su propia ciencia ${ }^{4}$. Con todo, la adhesión de los profesionales de la sociología a los métodos cualitativos no es en absoluto mayoritaria y más bien podría hablarse todavía de polémica o combate entre los partidarios del estudio de casos y aquellos más apegados a la cuantificación y la tradición positivista ', que desconfían de la validez como prueba de las historias de vida enfrentándola a la mayor capacidad de representatividad, predicción y verificación conseguida a través de los métodos estadísticos".

En el camino de búsqueda de un estatus para la sociología equiparable al de las ciencias físico-naturales, la metodología basada en las biografías y el estudio de casos, magistralmente desarrollada por la escuela de Chicago en los años veinte y treinta, se consideró obsoleta y fue prácticamente abandonada. En los años sesenta, y coincidiendo con un gran interés por los documentos personales entre los antropólogos, historiadores y psicólogos, la técnica fue redescubierta en el campo de la sociología. Como apunta J. Balán ?, este renacimiento tiene que ver con un cambio de orientación en las ciencias sociales, demasiado dirigidas desde la II Guerra Mundial hacia modelos que imitaban mecánicamente los de las ciencias físiconaturales, creando un lenguaje teórico cada vez menos accesible a los profanos y un tipo de investigación muy marcada por el lenguaje y las formas de presentación habituales en las publicaciones sobre aquéllas. Todo ello ha conformado un crecimiento acentuado de lo que Balán llama «orientaciones humanísticas» en las ciencias sociales. Este acercamiento, no sólo metodológico, de disciplinas como la historia, la etnología y la sociología, interesadas todas de nuevo por los «procesos sociales básicos de la interacción cotidiana» ${ }^{8}$, puede tener en la perspectiva biográfica un lugar privilegiado, en cuanto que, dentro de ella, la tradicional separación de ciencias sociales y humanidades queda desdibujada".

\footnotetext{
4 J. F. MARSAL, op. cit., p. 43.

5 Francesc HERNÁNDEZ, «El relato biográfico en sociología», Revista Internacional de Sociología, 44 (1986), pp. 278-9; Daniel BERTAUX, "L'imagination methodologique», Revista Internacional de Sociologia, 44 (1986), pp. 265-7.

6 F. HeRnÁNDEZ, op. cit., pp. 287-9.

7 Jorge BALÁN, «Introducción» a Las historias de vida en ciencias sociales. Teoría y técnica (Buenos Aires: Nueva Visión, 1974), pp. 8-11.

8 Ibid., p. 10.

9 F. Ferrarrotti, Histoire et histoires de vie (Paris: Klincksieck, 1983).
} 
Aunque los orígenes de la biografía estén en la literatura y en la historia, el género se consolidó en las ciencias humanas y sociales de forma preeminente gracias a la etnología, y gran parte de su popularidad actual se debe a un antropólogo: Oscar Lewis ${ }^{10}$.

La evolución del empleo de documentos personales en etnología (biografías, autobiografías, extractos de vidas, etc.) es similar a la ocurrida en sociología. En un principio las autobiografías se utilizaron con un carácter meramente documental y como una más de las técnicas útiles en el trabajo etnográfico de campo. A partir de la publicación en 1920 de The Autobiograpby of a Winnebago Indian por Paul Radin, y hasta los años cuarenta, fueron apareciendo toda una serie de biografías de indígenas, hechas con criterios más avanzados ". Después de una época de abandono, en que la etnología estuvo preocupada por asuntos teóricos y no tanto por la labor de salvaguarda documental, a la que se consideraban ligadas las biografías, éstas tomaron de nuevo impulso en los años sesenta, hasta el punto de que tal aproximación se ha convertido prácticamente en una subdisciplina $"$.

Sin embargo, la proliferación del empleo de biografías y documentos personales en la etnología no ha ido acompañada de una clarificación del campo de estudio, ni se ha conseguido definir con mayor coherencia qué es lo que se pretende estudiar y cómo hacerlo. Por un lado están los problemas técnicos sobre los que se ha reflexionado (diferencia entre cultural e idiosincrático, uso de intérpretes, entrevistas estructuradas, etc.) y que comienzan en el mismo momento de definir qué es una «historia de vida», tal como se emplea el término en sociología y etnología ${ }^{13}$. Pero, por otro, y en relación con estos problemas, es preciso plantearse una serie de cuestiones básicas, como la naturaleza de la memoria o el carácter complejo de la traducción etnográfica a

11) Ver las obras fundamentales de Oscar Lewis, Antropologia de la pobreza: cinco familias (México: F.C.E., 1961); Los hijos de Sánchez (México: F.C.E., 1964); Pedro Martínez (México: J. Mortiz, 1966); La vida. A Puerto Rican Family in the Culture of Pov'erty (New York: Random House, 1966).

"J. F. MARSAL, op. cit., p. 44.

1: Edmundo Magaña, «Reminiscencias personales de un indio tarëno», Arbor, 515516 (1988), p. 177.

1: Stanley BRANDES, «Les autobiografies etnografiques en l'Antropologia americana», Arxiu d'Etnografia de Catalunya, 2 (1983), 102-114 [original inglés, 1979]; F. MERCADÉ, «Metodología cualitativa e historias de vida», Revista Internacional de Sociologí, 44 (1986), p. 305. 
los cuales los etnógrafos que recogen biografías no parecen haber prestado demasiada atención ${ }^{14}$.

No obstante lo anterior, sí puede tenerse por cierto que, tanto por el volumen de investigaciones como por la considerable influencia de alguna de ellas, las biografías son en la etnología una aproximación con una tradición y un índice de aceptación mayor que en otras disciplinas sociales ${ }^{15}$.

\section{LA BIOGRAFÍA EN LA HISTORIA DE LAS CIENCIAS}

Tras la breve introducción anterior, y dado que el tema que en este trabajo se trata se refiere al uso de la biografía en la historia de la antropología, nos interesa sobre todo acudir ya a una disciplina concreta: la historia de las ciencias. Aquí la utilización del método biográfico no es, ni mucho menos, mayoritaria y existe cierta controversia en torno a ella, que está en relación con otras polémicas más generales como las que se desarrollan sobre la distinción entre historia y sociología de las ciencias, o entre internalismo y externalismo en su estudio. En suma, cuestiones que afectan a la propia definición del objeto de la historia de las ciencias, porque la discusión se centra en aceptar dentro de su campo la historia de los científicos o incluir sólo el desarrollo de las ideas y los descubrimientos, con independencia de quienes hayan sido sus creadores.

Es evidente que la postura ante esta cuestión depende en gran medida de la disciplina de origen del investigador y los temas de trabajo elegidos, tendiendo los filósofos de la ciencia, epistemólogos y los propios científicos (física, química, matemáticas, ciencias naturales) a ser más internalistas que los que tienen una formación profesional como historiadores o sociólogos de la ciencia y, lógicamente, que los científicos sociales. Estos se inclinan más, podríamos decir, a la «historia» que a la «ciencia», en cuanto que consideran que la historia de la ciencias, como cualquier género de historia, trata de un acontecer humano, que no puede entenderse completamente sin tener en cuenta el medio, el contexto social e individual en que se desarrolla.

14 Ver E. MAGAÑA, op. cit., pp. 178-186; L. L. LANGNESS, The Life History in Anthropological Science (New York: Rinehart and Winston, 1965); L. L. LANGNESS and C. Frank, Lives. An Anthropological Approach to Biography (Los Ángeles: Chandler and Sharp Pub., 1981).

is S. BRANDES, op. cit., pp. 114-117. 
Para los internalistas, preocupados por una historia meramente intelectual que explique el sucesivo avance de las ideas científicas, la recurrencia a cualquier información biográfica no tiene apenas objeto. Un ejemplo claro de esta postura puede ser el texto de $H$. Metzger (en su libro de historia de la química de 1923) que reproduce R. Taton ${ }^{16}$ :

La historia de las doctrinas químicas, tal y como hemos intentado trazarla, es independiente de la historia de la vida de los sabios. Para no prolongar inútilmente nuestro texto, hemos eliminado de este trabajo toda noticia biográfica, como también toda apreciación sobre la psicología de los autores estudiados.

Incluso en otros párrafos de esta autora y algunos más, reproducidos también por Taton ${ }^{17}$, se asimila la biografía con lo anecdótico o pintoresco, reduciéndola así a un género de información o conocimiento que poco tiene que ver con su elevado intento de llegar a aprehender las causas del verdadero (¿único?) proceso por el que el pensamiento humano ha ido progresando en el descubrimiento de la ciencia.

Esta posición no sólo es característica de una determinada época (anterior a la II Guerra Mundial) y de obras dirigidas a los estudiosos de las ciencias físico-naturales, sino que ha vuelto a reproducirse, incluso con mayor fuerza, entre historiadores de las ciencias con formación de filósofos, lógicos y epistemólogos, que desprecian el particularismo histórico, la documentación detallada de hechos y períodos y, por supuesto, de las vidas, porque esto nada puede aportar a su objetivo de lograr grandes leyes explicativas de la evolución del conocimiento basadas en métodos lógicos.

Pero, al mismo tiempo, otros estudiosos se han visto enfrentados, precisamente por el auge, la diversificación de la disciplina y la complejidad de algunos de sus problemas, a la necesidad de buscar una concepción global del desarrollo científico, en la que los factores psicológicos, económicos, institucionales y políticos juegan un papel importante. En este segundo tipo de historia es claro que las biografías cumplen una función significativa, al situar la labor científica de un autor en el curso de su proceso vital individual y también en el ambiente científico e ideológico del momento ${ }^{18}$.

16 René TATON, "Las biografías científicas y su importancia en la historia de las ciencias», en A. Lafuente y J. Saldaña (eds.), Nuevas tendencias. Historia de las ciencias (Madrid: CSIC, 1987), p. 76.

I Ibid.. pp. 74, 76.

is Ibid., p. 77. 


\section{BIOGRAFÍA Y ETNOLOGÍA}

Sabiendo que, en la discusión teórica dentro de la historia de las ciencias, las particularidades de las humanidades y disciplinas sociales no son tenidas en cuenta, nos centraremos ahora en el interés creciente por las biografías despertado en la etnología. Este ya no sólo se centra, como vimos, en historias de vida o autobiografías de individuos de otras culturas (objeto de estudio clásico de la disciplina), sino muy especialmente en las vidas y circunstancias de trabajo de campo de los mismos antropólogos (lo que se ha llamado «etnografía de los etnógrafos»). Aunque el debate de lo que S. A. Tyler ha denominado antropología postmoderna no se circunscribe prioritariamente a la historia de la antropología, sino que intenta ser un nuevo enfoque teórico para la investigación general, en algunos aspectos, y en lo que tiene de revisión crítica del pasado, sí puede tener una aplicación a la historiografía.

La cercanía entre literatura y antropología - y por tanto la posibilidad de analizar al antropólogo como «autor» y a sus obras con las técnicas de la crítica literaria - y la atención a las circunstancias vitales del etnógrafo (especialmente las del trabajo de campo que determinan su labor como «traductor» de culturas) son elementos claves para esta nueva visión de la investigación, que puede llevarse tanto a la situación actual y prospectiva como al pasado histórico.

Una de las características de la etnología es que su materia prima se obtiene a partir de una relación vital intensa entre el observador y los observados. Sin embargo, en la exposición de los resultados del trabajo de campo, el etnólogo, guiado por criterios de objetividad científica en el tratamiento de lo visto, no podía considerar ni pertinente ni necesario entrar en detalles sobre los elementos subjetivos de su investigación, que podrían restarle credibilidad. Se eludían por tanto los elementos biográficos, con el resultado paradójico de que el éxito de su obra dependía de su habilidad para mostrarnos su autoridad, emanada del hecho de «haber estado allí», pero sin aportar muchos más datos sobre el «cómo» y «por qué» había estado allí, y con quién.

En escritos que han obtenido amplia difusión, tanto C. Geertz ${ }^{19}$ como otros ${ }^{20}$ han expuesto la imposibilidad de separar el trabajo etno-

19 Clifford GeERTZ, El antropólogo como autor (Barcelona: Paidós, 1989).

20 Ver por ejemplo el artículo de $M$. Louise PratT, «Trabajo de campo en lugares comunes», en James ClifFord y George E. MARCus (eds.), Retóricas de la Antropología (Gijón: Júcar, 1991), pp. 61-90. También, en un sentido más autobiográfico, Paul Rabinow, Reflections on Fieldwork in Morocco (Berkeley and Los Ángeles: University of California Press, 1977). 
gráfico de la personalidad y experiencia de su autor. El etnógrafo interpreta otras culturas, se involucra en ellas y las traduce para nosotros, influyendo en esa traducción el tipo y la profundidad del contacto que haya logrado establecer. Por tanto, lo biográfico no puede ser visto en oposición a lo científico; más bien habrá que contar con que la experiencia biográfica (subjetiva) está en la base de cualquier interpretación, y que esto no equivale necesariamente a falsedad ${ }^{21}$.

Incluso se puede apreciar últimamente, como subproducto, el surgimiento en la literatura antropológica de un género dedicado a la narración de las peripecias de los etnógrafos en sus trabajos de campo; género que, aparte de desmitificar determinados axiomas metodológicos de la disciplina, encuentra amplio eco en capas de lectores ajenos a la profesión, como muestra el éxito del libro de Nigel Barley ${ }^{22}$.

En la historia de las ciencias ha existido una tendencia dominante a la discriminación y a considerar únicamente aquellas líneas de investigación, autores, teorías, etc., que podían juzgarse como iniciadores o precursores de los principios vigentes en la actualidad que, a su vez, se consideran los más perfectos o avanzados entre los varios que pueden coexistir en una determinada disciplina. Así, es posible contar versiones historiográficas guiadas por principios de legitimación o defensa del evolucionismo, la escuela boasiana, la antropología social británica, el funcionalismo, el materialismo cultural, etc. ${ }^{23}$.

$\mathrm{Si}$, según esto, se considera la relación entre teoría vigente en un momento dado y actividad historiográfica paralela, no sería de extrañar que, acompañando a la renovación de la antropología que intentan algunos investigadores, como los arriba citados, asistiéramos a un incremento del interés por una historia «literaria» de la antropología, con los grandes autores como hilo conductor, muy centrada en el análisis de textos y biografías de los antropólogos clásicos. El enorme eco de algunas autobiografías ${ }^{24}$, memorias, dia-

$\because$ Estos aspectos aparecen ampliamente desarrollados por distintos autores en uno de los libros emblemáticos de la antropología postmoderna, J. Clifford y G. F. Marcus (eds.), Retóricas de la Antropologia (Gijón: Júcar, 1991) [original inglés, 1986].

$\because \quad$ El antropólogo inocente (Barcelona: Anagrama, 1989).

$\therefore$ Francisco Castilla Urbano, "La historia de la antropología como excusa: la influencia de la metodología en la disparidad historiográfica», RDTP. XLV (1990), pp. 21-41.

21 Ver, por ejemplo, la de Margaret MEAD, Experiencias personales y científicas de una antropóloga (Barcelona: Paidós, 1987) |original inglés 1972]. Como testimonio vivido de una etapa importante de la historia de la antropología es significativo el articulo de Hilda Kuiper, «Function, History, Biography (Reflections on Fifty Years in the British Anthropological Tradition)», en G. W. STOckING (ed.), Functionalism 
rios ${ }^{25}$ y correspondencias ${ }^{26}$, aseveran la vigencia de este enfoque que reivindica el entronque de la antropología con ciertos modos de conocimiento más humanísticos que cercanos a las ciencias de la naturaleza.

No obstante lo anterior, esta actitud, que podríamos decir más biografista, en la antropología y su historia no debería juzgarse tan solo a la luz de las modas teóricas actuales, dado que es mucho más antigua ${ }^{27}$. La investigaión etnográfica conlleva un tipo de relación especial con el objeto de estudio y esta particularidad debe ser siempre tenida en cuenta por el historiador, por más que su objetivo general no sean los casos de científicos, sino los descubrimientos en el desarrollo de un conocimiento objetivo. Aunque pueda hablarse de historia de las ciencias como una disciplina única, es obvio que cada materia, en base a su objeto, metodología y alcance, requiere un tratamiento adecuado a esas particularidades y, quizá, en el caso de la antropología uno de estos sesgos necesarios sea la atención a las biografías.

Puede considerarse un ejemplo poco serio y discutible, pero, a pesar de que la narración de cualquier descubrimiento científico pueda ser apasionante, quizá, y tal como se producen los hechos en general, la atracción que logra suscitar la narración de las relaciones establecidas entre un físico nuclear y su laboratorio no llegue a ser tan intensa como cuando el caso se refiere al enfrentamiento de un etnógrafo con una comunidad de hombres culturalmente distintos. Con todo, marcar diferencias de este tipo entre las ciencias humanas y las físico-naturales, no ha de ser entendido como un signo de asentimiento respecto a la inferioridad de las primeras en cuanto a conocimiento científico. De hecho, lo que llevaría a esta última conclusión sería la adopción de un modelo excesivamente mimético respecto a las ciencias de la naturaleza.

\section{GÉNEROS BIOGRÁFICOS EN LA HISTORIA DE LA ETNOLOGÍA}

Si centramos la cuestión en la historia de la etnología, vemos que tradicionalmente la base ha sido biográfica. La mayoría de las historias

historiced (Madison: U. of Wisconsin Press, 1984) (History of Anthropology, volume 2), pp. 192-193.

25 Los más importantes, sin duda, por la trascendencia que han tenido, son los de Bronislaw Malinowski, Diario de campo en Melanesia (Barcelona: Júcar, 1989) [original inglés 1967].

26 Por ejemplo, de M. MEAD, Cartas de una antropóloga (Barcelona: Bruguera, 1983) [original inglés 1977].

27 Cf. M. MEAD, Cartas de una antropóloga, cit., pp. 6-11. 
consisten en una enumeración cronológica de teorías o movimientos de escuela, pero en el interior de estos capítulos lo que se encuentra frecuentemente es una sucesión de figuras, siguiendo el esquema, clásico desde el siglo XIX, de vida y obra. Ambos tratados críticamente, más que por la trascendencia de los descubrimientos, en función de la mayor o menor afinidad con la postura teórica del autor.

Se seleccionan así no sólo los antropólogos que deben aparecer en el tratado, sino el mismo enfoque que se da a su trabajo, con criterios muy parciales que no tienen que ver con la investigación histórica. Se trata pues de historias cuyo defecto no radica esencialmente en ser biográficas (mejor podríamos llamarlas genealógicas), sino en estar concebidas con otros objetivos distintos a los del mero conocimiento del desarrollo de la disciplina. En ellas es criticable el uso que hacen de las biografías y cómo están éstas elaboradas, pero como un elemento más que pone en evidencia los problemas epistemológicos de la antropología y la falta de profesionalidad en el tratamiento de su historia ${ }^{28}$. En realidad, en estas historias clásicas se puede rastrear el género de las biografías profesionales o de grandes hombres, un culto a los ancestros, a los fundadores de las más importantes escuelas, cuyos méritos resultan aún más preclaros si se les confronta con sus oponentes coetáneos o incluso con el mismo autor de la historia.

Un ejemplo claro de historia basada en la sucesión de autores y con un obvio partidismo por algunos de ellos, es la clásica de Robert Lowie ${ }^{20}$. Pero este tipo parece no ser tampoco una reliquia del pasado cuando no hace mucho que hemos asistido a la publicación de un libro póstumo de Evans-Pritchard "30, tanto más exagerado que el de Lowie en los dos aspectos que comentamos: una historia de la antropología consistente en la enumeración de los más dispares precedentes (con tratamiento biográfico poco riguroso) y en el ensalzamiento o la crítica ácida de los mismos según una perspectiva totalmente presentista. Podría aducirse a su favor que se reúnen ensayos y notas dispares, y que la publicación definitiva de los mismos por parte de EvansPritchard tal vez no hubiera adoptado la presente forma, pero el hecho es que no se trata de un libro aislado, sino que se incluye en una tendencia a considerar la historia de la antropología más que como

28 Joseph R. Llobera, Hacia una bistoria de las ciencias sociales (Barcelona: Anagrama, 1980), pp. 19-20.

29) Historia de la Etnología (México; F.C.E., 1946) [original inglés 1937]. 1981].

i) Historia del pensamiento antropológico (Madrid: Cátedra, 1987) [original inglés 
una subdisciplina, como un subproducto que surge en algún momento de la carrera académica de muchos de los antropólogos consagrados ${ }^{31}$.

Esta clase de trabajos se puede relacionar, de algún modo, con otro género biográfico que también tiene mucho que ver con las estructuras académicas; se trata de las reseñas de vida, recuerdos, homenajes y necrologías. Muchos de los escritos de carácter histórico debidos a antropólogos fueron hechos con motivo de conmemoraciones de instituciones o personas, lecciones inaugurales de cátedras y cursos universitarios, y otros acontecimientos de idéntico cariz. (Tal vez en esto tiene que ver la común idea de que la historia del desarrollo de una disciplina es un buen medio de iniciación a la misma para los estudiantes). La costumbre de escribir semblanzas biográficas de investigadores y profesores ilustres ha contribuido tradicionalmente a que algunos autores poco inclinados a la investigación histórica acometieran una mínima labor dentro de la misma, al reseñar las contribuciones de colegas, maestros o compañeros, con los que les unió una relación vital o intelectual. En realidad, este tipo de trabajos cumple sobre todo una función académica, encaminada más a la creación y afirmación de la identidad de cada disciplina dentro del medio que al propio conocimiento de su historia. Por otro lado, no hay que olvidar que se trata de semblanzas laudatorias, encargadas a personas y publicadas por instituciones ligadas a la figura que se pretende homenajear y hacia la cual desean manifestar de esta manera su gratitud. Esto implica que generalmene sólo los aspectos positivos serán reseñados o, cuando menos, que serán resaltados por encima de los defectos o fracasos.

Otra limitación de las semblanzas radica en estar constreñidas por una forma normalizada y por la brevedad. Normalmente se expone una sucinta biografía, con especial hincapié en los datos profesionales, seguida por la valoración de las contribuciones científicas e institucionales más importantes y una relación bibliográfica más o menos extensamente comentada. Aún así, las notas necrológicas varían en gran manera, tanto en extensión como en contenido, dependiendo de su autor y del carácter del biografiado, llegando en algunos casos a ser documentos dotados de originalidad y con gran valor para el conocimiento de una comunidad científica. En esas circunstancias, pueden resultar de gran ayuda al historiador en un primer acercamiento a ciertas personalidades, sobre las que no sólo proporcionan un esquema de datos objetivos, sino también una visión interna que interesa, aunque pueda ser subjetiva, en cuanto que es producto de un contacto personal directo y, por lo tanto, vivo

31 J. R. LlObERA, op. cit., p. 17. 
e insustituible. Además pueden ser valiosas para la formación de una idea interna sobre el ambiente, la consideración y el estado de ciertas cuestiones en un momento preciso de la disciplina.

En suma, si bien es cierto que el carácter histórico de las semblanzas biográficas de tipo académico es relativamente menor, no pueden tampoco despreciarse del todo como fuentes que, tratadas con un criterio acertado, no dejan de ser útiles en la investigación sobre historia de la ciencia. En otro sentido, tal vez puedan ser vistas como un precedente, con otros métodos y distintos fines, de las modernas biografías científicas.

\section{PROBLEMAS METODOLÓGICOS DE LAS BIOGRAFÍAS DE CIENTÍFICOS}

Dejando ya a un lado los distintos géneros biográficos que existen en las ciencias sociales y humanas, será conveniente analizar a continuación algunas cuestiones metodológicas con respecto a las biografías históricas de científicos.

La base de partida es que el objeto de estudio de la historia de las ciencias está en las ideas y métodos científicos y el progreso de los descubrimientos en cada una de sus ramas. Sin embargo, la mayoría de los historiadores consideran que este análisis no puede hacerse sin tener en cuenta el contexto histórico general y los factores externos que contribuyen a la evolución científica. Estos objetivos generales, como es lógico, se captan mejor en temas más concretos y algunos autores ${ }^{32}$ se inclinan a pensar que el estudio de un científico particular, su obra y los elementos que influyeron en ella, puede ser un caso muy indicado para llevar a cabo la síntesis de aquellos factores.

Aceptar esto no supone creer que la historia de una disciplina, un problema o un período, se reduce a la suma de una serie de biografías - como hemos visto que ocurre con frecuencia en antropología. Es necesario tener en cuenta otra serie de elementos, tanto internos de progreso como externos de carácter no individual. El enfoque biográfico sería, por tanto, uno de los posibles, mejor adaptado a ciertos temas, ciencias particulares o problemas, y no incompatible con otros métodos. Ahora bien, las buenas biografías serán útiles siempre. Su valor radica en que pueden constituir modelos a partir de los cuales puede entenderse el análisis global de los problemas de la historia de la ciencia, considerados en toda la complejidad de un ambiente concreto. Constituyen, por ello mismo, puntos de partida para investigaciones de otro

3 R. TATON, op. cit., p. 78. 
tipo, además de su aportación intrínseca de elementos documentales y expositivos de un ejemplo particular ${ }^{33}$.

A pesar de todo, ya vimos que muchos historiadores de la ciencia no admiten la inclusión de las biografías dentro de su campo. Por otra parte, el descrédito de la historia biografista, acrítica y poco rigurosa, habitual en el siglo XIX y principios del XX, compuesta por la enumeración de grandes sabios, sus anécdotas y descubrimientos sobresalientes, ha sido la causa de que otros muchos se hayan desinteresado de la poco prestigiosa investigación biográfica. Sin embargo, es injusto juzgar tan pobremente un método que puede dar mucho mejores resultados, claro es, siempre que se practique con el rigor necesario.

Dentro de la historia de las ciencias, y lógicamente de la antropología, el objetivo de la biografía será llegar a ver cómo se ha producido una obra de creación, en la que intervienen todos los condicionamientos, internos a la ciencia, externos a ella y psicológicos del individuo. Para su tratamiento, el esquema general deberá basarse en una investigación precisa de los elementos históricos generales, acontecimientos de la vida personal, obra impresa e inédita, y otros documentos personales como la correspondencia; formación e influencias recibidas y, finalmente, aportaciones y trascendencia de la figura en cuestión ${ }^{34}$.

Algunas biografías de científicos consisten precisamente en este aporte documental; pueden exponer, por ejemplo, pormenorizadamente los elementos biográficos, extractos de manuscritos y cartas. Pero esto no es suficiente si no se aborda una interpretación que abarque todos los aspectos de la vida y la discusión rigurosa de la obra, con sus aportaciones e influencias, intentando una visión que integre todos los factores, incluyendo las propias contradicciones. Partiendo de estas ideas, el historiador de las ciencias T. L. Hankins en un artículo "s, que sigue y matiza R. Taton ${ }^{36}$, propone ciertas reglas a seguir en la elaboración de una biografía.

En primer lugar señala que no debe perderse de vista que el estudio versa sobre la ciencia y la intención es exponer cómo un científico consiguió llevar a cabo su obra; con qué objetivo, a través de qué pasos y de qué manera. Los dos puntos claves para ello serán la ordenación y el conocimiento exhaustivo de toda la documentación disponible del

33 Ibid.

34 Ibid., p. 82.

35 Thomas L. HANKINS, "In defence of Biography: the Use of Biography in the History of Science», History of Science, XVII (1979), pp. 1-16.

36 Op. cit., pp. 79-81. 
autor, incluidos los manuscritos, y la capacidad para hacer inteligibles al mayor número de lectores posible los elementos especializados del área a la que pertenezca el trabajo del biografiado. Es verdad que esta es una dificultad mayor en unos campos, por ejemplo las matemáticas, que en otros, como la misma etnología, pero aun así la intención y el conocimiento de la materia necesarios para resolver los problemas son imprescindibles.

En segundo lugar, aparece la necesidad de mostrar la actividad del científico de forma integrada, con los diversos elementos e influencias que la conforman, hasta llegar a exponer una imagen coherente del mismo. Señala Hankins que algunos conceptos básicos en el desarrollo de las ciencias se han formado a base de contribuciones individuales sucesivas, por lo que los análisis biográficos pueden ser muy útiles para reconstruir la historia de dichas nociones. En el caso de la etnología esto es especialmente claro con referencia, por ejemplo, al concepto de función y B. Malinowski.

Una tercera norma hace hincapié en la agilidad de la lectura que debe caracterizar el estudio. La dificultad radica en conseguir un equilibrio entre la presentación del carácter y las actividades del autor - ninguna de la cuales puede ser eludida aunque sean del todo ajenas a su labor de investigación, a riesgo de ofrecer una semblanza falseada de la personalidad del mismo- y la reconstrucción del proceso intelectual de elaboración de su obra. Mantener una línea clara que guíe el trabajo sin caer ni en el anecdotario aislado y particularista, por un lado, ni en el tecnicismo o la construcción teórica del conocimiento, por otro, sería la regla de conducta. Si tenemos en cuenta la gran variabilidad y número de factores que hay que combinar - externos (ambiente científico, institucional, general), circunstancias personales (psicológicas, familiares, sociales, políticas), internos a la propia disciplina (abstracción, experimentación) - puede advertirse lo complicado que resulta llegar a obtener una «buena» biografía científica. A estos problemas pueden además unirse otros ajenos al mismo esquema metodológico; por ejemplo, escasez de obra publicada del autor que se estudia, material inédito fragmentario, falta o dificultad de acceso a manuscritos personales, etc. $O$ de otro tipo, como que la materia sea delicada, o difícil de aplicar a su historia elementos externos; así ocurre con las matemáticas, aunque no es, precisamente, el caso de la etnología, en cuyo desarrollo no cuesta ver interactuando elementos externos o biográficos.

En ciertos casos, la confluencia de varias de estas circunstancias condiciona la aparición de biografías de algunos científicos o hace que las existentes no sean muy satisfactorias. Poder contar con ediciones críticas 
de obras, manuscritos y correspondencias es siempre una gran ayuda. En ocasiones esta labor previa es imprescindible para acometer el estudio biográfico de un científico de envergadura ${ }^{37}$; en otras, la aparición posterior de este tipo de documentos lleva a un replanteamiento de las visiones anteriores sobre el carácter y la labor de la figura en cuestión (es un ejemplo claro el nuevo punto de vista que proporcionan los diarios de Malinowski publicados en 1967) ${ }^{38}$.

Pero, aun dejando de lado estos escollos instrumentales, sigue existiendo el problema fundamental al que antes se ha aludido: la necesidad de obtener una imagen total del científico que aúne el proceso de creación de su obra y su vida, tratada con la mayor amplitud posible. Esto requiere la presentación integrada del análisis de la contribución científica y el estudio biográfico, y supone un reto para no restar finalmente claridad e interés al trabajo. Por eso, y aunque no es un procedimiento deseable, es muy frecuente encontrar separados los dos temas, incluso en el título de los estudios, en los dos clásicos epígrafes «vida y obra» ${ }^{39}$.

UTILIDAD DEL ENFOQUE BIOGRÁFICO EN LA HISTORIA DE LA ETNOLOGfA ESPAÑOLA

Después de estas apreciaciones metodológicas de carácter general, centraremos el tema en el caso concreto de la historia de la etnología en España y la investigación que hay sobre ella.

En el desarrollo de la ciencia española, al menos de la época contemporánea, hay una serie de condicionantes externos que han afectado a todas las disciplinas y han tenido una manifestación específica en la etnología. La falta de continuidad y de correcta institucionalización académica, así como el aislamiento social de la labor investigadora son los más generalmente considerados por sociólogos e historiadores, junto a problemas de tipo interno, tales como falta de profundidad teórica, mimetismo respecto a las áreas centrales del progreso científico o carencia de experimentación, también aducidos con frecuencia.

Si partimos de este panorama nacional, evocado ya desde antiguo y, desde luego, muchísimo más complejo de lo que aquí sólo se ha enunciado mínimamente, nos encontramos con una historia más hecha

37 Ronald P. RoHner (ed.), The Ethnography of Franz Boas. Letters and Diaries of F. B. written on the NW Coast from 1886 to 1931 (1969).

38 B. MALINOWSKI, op. cit.

39 R. TATON, op. cit., p. 81. 
de figuras que de escuelas y más sustentada por personas que por instituciones. $\mathrm{O}$, tal vez, esta es la lectura historiográfica más común de nuestro pasado científico y hay otras posibles que contemplar; porque, al tratar este problema, no puede, obviamente, olvidarse la falta de desarrollo de los estudios sobre historia de las ciencias en nuestro país hasta época muy reciente.

En resumen, nos encontramos, por un lado, con una disciplina que ha ido progresando con bastantes dificultades, y, en consecuencia, por otro, con un conocimiento histórico de la misma defectuoso. Las dos circunstancias tendrán sus consecuencias directas en el tipo de trabajos históricos con que contamos hasta ahora y en los que se plantean para el futuro.

Al hacer un repaso de esta bibliografía observamos que en publicaciones debidas a antropólogos e historiadores de la antropología no predomina el análisis de la evolución de conceptos o formulaciones teóricas, aunque hay algunos muy considerables ${ }^{40}$. Tampoco aparecen muchos esfuerzos encaminados a elaborar una historia general (internacional) de la disciplina y menos aún referidos al marco estatal. En cambio, se insiste en investigar tradiciones científicas de ámbitos regionales parciales. El conocimiento de los cauces institucionales y editoriales por los que ha transcurrido la materia es en general, y a pesar de contar con algunos estudios monográficos interesantes, escaso, comparado con el número de publicaciones de género biográfico ${ }^{41}$.

Ahora bien, dentro de estas últimas, y bajo la relativa abundancia de títulos, encontramos disparidad de formas, enfoques y objetivos, además de grandes lagunas. En este sentido, podría citarse en primer lugar, la vigencia de las necrologías; no sólo su redacción en la actualidad (algo lógico y normal en cualquier comunidad científica) ${ }^{42}$, sino,

*) Por ejemplo el libro de Fernando Estévez GonzÁlez, Indigenismo, Raza y Evolución. El pensamicnto antropológico canario (1750-1900) (Santa Cruz de Tenerife: Museo Arqueológico y Etnográfico de Tenerife, 1987).

"Evaluaciones de la bibliografía sobre historia de las ciencias antropológicas en España pueden verse en Carmen ORTIZ GARCíA, «La investigación española sobre historia de la antropología. Un ensayo de clasificación», IV Congreso de Antropología (Alicante) (1987), 29 pp., s.p., y en Llorenç PRATs, «La historia del folklore en Cataluña. Estado de la cuestión», IV Congreso de Antropología (Alicante) (1987), 22 pp., s.p.

4 . Por reseñar sólo algunas, J. CARo Baroja, «Elogio de D. Telesforo de Aranzadi (1860-1945)», RDTP, XVII (1961), pp. 136-144; J. Caro Baroja, "Don Luis de Hoyos Sáinz (1868-1951)», Publicaciones del Instituto de Etnografía y Folklore "Hoyos Sáinz", 3 (1971), pp. 7-18; Fermín Del PINo Diaz, «En memoria de Juan Comas (1900-1979)», Revista de Indias, XXXVIII, núm. 153-154 (1978), pp. 355-367; Joan Josep PUJADAS, "Breu sboç de la vida i obra de J. M. Batista i Roca, amb motiu de la seva mort», 
de forma significativa, el hecho de que sean casi la única información detallada con la que contamos sobre algunos autores. Es el caso de Manuel Antón, una figura básica, al menos como introductor de la antropología en el mundo académico, y sobre el que sigue siendo fundamental recurrir a su semblanza necrológica como información editada más completa ${ }^{43}$. Lo cierto es que todavía hay una gran cantidad de figuras sobre las que falta un estudio biográfico de entidad, difícil de emprender a veces por la misma carencia de documentación o la dificultad de acceso a ella, dada la dispersión de los fondos documentales personales. Un ejemplo podría ser el análisis de la vida y obra de Joaquín Costa en su faceta de etnólogo, sobre el que hay, no obstante, un interés antiguo ${ }^{41}$ y una iniciativa reciente ${ }^{15}$.

Un segundo aspecto remarcable sería la falta de independencia formal y la instrumentalización frecuente del enfoque biográfico. Ya se ha hecho referencia a la utilidad, y en algunos casos mera necesidad, de la edición crítica de manuscritos, documentos y correspondencias, sin contar con los cuales a veces no es posible acometer un análisis biográfico de calidad. A esto hay que unir la reciente eclosión de reediciones de obras consideradas clásicas. En ambos casos es frecuente encontrar el acompañamiento de un estudio introductorio crítico y biográfico, en ocasiones valioso, como los incluidos en ediciones de obras de A. Machado ${ }^{46}$, C. Bernaldo de Quirós ${ }^{47}$, A. Guichot y

Quaderns de l'Institut Català d'Antropologia, 1 (1980), pp. 99-111; Gonzalo Aguirre Beltrán, «Necrologia d'Angel Palerm Vich», en Neus EsCANDELL i Ignasi TERradas (eds.), Història $i$ antropologia a la memòria d'Ángel Palerm (Montserrat: Publicacions de l'Abadia de Montserrat, 1984), pp. 7-20.

43 Domingo SÁNCHEz, «El Excmo. Señor D. Manuel Antón y Ferrándiz», Actas y Memorias de la Sociedad Española de Antropología, Etnografía y Prebistoria, X (1931), pp. 13-30.

${ }_{44}$ Tomás Carreras Artau, «Joaquim Costa i els estudis consuetudinaris a Espanya (Una excursió de Psicologia i Etnografia hispanes)», Estudios Filosóficos (Barcelona: CSIC, 1966), I, pp. 156-201 [ed. original 1917].

45 De F. DEL PINO Díaz, "Joaquín Costa antropólogo», Cuadernos Altoaragoneses de Trabajo, 7 (1987), pp. 28-32 y «Texto original de Joaquín Costa para convocar los premios de la Academia de Ciencias Morales y Políticas (Madrid, 1897-1917)», Boletín de Historia de la Antropología, 2 (1989), pp. 29-36. Ver, asimismo, su artículo en este mismo volumen de la RDTP.

46 José Blas Vega y Eugenio CoBo, «Estudio preliminar», El Folk-Lore Andaluz (Madrid: Tres-Catorce-Diecisiete, 1981), pp. v-xlv.

47 Aunque su autor no es historiador de la antropología, merece atención el trabajo de José Luis GARCía DELGADO, «Estudio preliminar» y «Relación de las obras de Constancio Bernaldo de Quirós», en C. BERnAlDo DE Quirós, El "Espartaquismo 
Sierra ${ }^{48}$ o V. Serra i Boldú ${ }^{49}$. Sin duda, este tipo de trabajos constituye un buen punto de partida para la elaboración de biografías científicas con un sentido más amplio ${ }^{50}$. Lo mismo puede decirse de la edición de importantes obras inéditas o de fragmentos de correspondencias, documentos personales y bibliografías ${ }^{51}$, pero, a pesar de su utilidad general, esta clase de publicación no puede sustituir al análisis completo de la vida del autor.

La dependencia instrumental de la biografía que hemos visto en el caso de las ediciones críticas y en otros géneros, como el homenaje o la necrología, puede rastrearse, con distinto sentido, en la utilización de ciertas figuras que se estudian en cuanto que sirven a otros enfoques metodológicos: por ejemplo, el análisis del surgimiento y evolución de nuestra materia de estudios en un ámbito regional. Puede decirse, efectivamente, que tal proceder es inevitable. Se alude a instrumentalización porque, al tratar a esos autores en parte como «héroes» o "padres», el objetivo deja de ser el conocimiento del investigador y su obra en el ambiente que la ha hecho posible y pasa a ser otro ajeno a la propia biografía científica. Siempre que tal análisis tenga el rigor histórico necesario, quizá no surja ninguna contradicción, ya que, en realidad, la consecuencia lógica sería terminar por situar a cada investigador en una línea, continua o no, de desarrollo de la disciplina. El problema puede surgir cuando, previamente y desde el presente, se escogen los generadores y jalones de una línea que interesa favorecer por cuestiones ajenas al transcurrir histórico.

Dando por establecido que la biografía no es excluyente con ningún otro método de investigación histórica, que puede resultar más apta para algún tipo de problemas que para otros $y$, finalmente, que no es de empleo mayoritario en la historiografía, no deja de resultar llamativo

agravio" y otros ensayos sobre la lectura económaca y social de Andalucía (Madrid: Ediciones de la Revista de Trabajo, 1973), pp. 9-51 y 342-365.

* José Ramón Jiménez Benftez, «Estudio preliminar», en Alejandro Guichot y Silerra, Noticia histórica del Folklore (Sevilla: Junta de Andalucía, 1984), pp. i-xi.

" Isidor CONSul. i Ramon MIRO, «Estudi preliminar», en Valeri SERRA i BOLdú, Folklore de la pagesia (Montserrat: Abadia de Montserrat, 1987).

s) $O$ bien son un producto menor, cuando el autor ha dedicado una atención monográfica a un investigador del pasado. Este sería el caso de la tesis de J. R. Jiménez BENITEZ, Alejandro Guichot y Sierra (1859-1914) (Universidad de Sevilla, 1984).

"Como ejemplo puede servir la publicación de dos importantes obras inéditas de Víctor Grau-Bassas, Usos y costumbres campesinos en Gran Canaria (Las Palmas: Museo Canario, 1980) y Viajes de exploración a diversos sitios y localidades de Gran Canaria (Las Palmas: Museo Canario, 1981). 
que las biografías con que contamos, referidas a la historia de nuestra antropología, sean la mayor parte de lo que se ha considerado fundadores de tradiciones nacionales o regionales dentro del estado español.

La primera razón que puede darse para este hecho es que son éstas las que cuentan con mayor labor de investigación hecha. Sin embargo, sin entrar a juzgar ahora las causas de la situación actual de nuestra historiografía, en lo que se refiere al tema que se trata sí parece existir algún tipo de prejuicio, que se manifiesta en el olvido, por parte de los antropólogos que hacen historia, de ciertas personalidades cuya obra debería situarles en un puesto privilegiado de nuestra historia.

Por citar nombres destacados, ni Costa (salvo las excepciones citadas y alguna más), ni Bernaldo de Quirós ${ }^{52}$, ni Carreras i Artau (hasta el reciente trabajo de L. Calvo) ${ }^{53}$, ni Sales y Ferré ${ }^{44}$, parecen resultar más atractivos que los etnólogos o folkloristas, quizá considerados más "profesionales» (en cuanto que no están adscritos, como los citados, a la historia de otras disciplinas), pero también centrados en investigaciones más locales.

En suma, la impresión, en líneas generales, es que las biografías están enfocadas también, como un porcentaje amplio del resto de los estudios, al análisis de tradiciones regionales y no suponen, por tanto, una vía distinta o con cierta independencia de la que hasta ahora resulta la dominante.

No obstante, ante la uniformidad que presenta el panorama actual de nuestra historiografía antropológica, la perspectiva biográfica podría ser muy fértil, al proporcionar esquemas alternativos y hacer posible un examen más profundo de algunas hipótesis. Una de las ideas que puede verse más extendida es que ha existido una cierta separación, o doble vía de evolución, de las ciencias antropológicas en España, perviviendo desde fines del siglo XIX hasta casi los años sesenta. Por un lado, se aprecia un desarrollo del folklore y los estudios de tradiciones populares, afincado sobre todo en ciertas áreas y ligado a movimientos románticos, conservadores y de reivindicación nacionalista: por otro, y con ciertos visos de oposición, una antropología «naturalista» practicada por hombres de ciencias, liberales, ligada al evolucionismo, centrada en

52 Sobre el que puede verse, no obstante, el trabajo de F. DEL PINO en "Antropólogos en el exilio», El exilio español de 1939 (Madrid: Taurus, 1978), VI, pp. 13-155.

53 Luis Calvo Calvo, La Antropología en Cataluña (1915-1970) (Barcelona: Universidad de Barcelona, Tesis Doctoral, 1989).

54 Sobre el que hay un estudio biográfico, publicado hace ya años, de Manuel NúÑEz ENCABO, Manuel Sales y Ferré: los orígenes de la sociología en España (Madrid: Cuadernos para el Diálogo, 1976). 
las áreas centrales del país y algunas periféricas, y aglutinada en torno a ciertas instituciones ss.

Mi trabajo sobre Luis de Hoyos Sáinz, para el que se manejaron documentos, no sólo publicaciones, pertenecientes al período cronológico que abarca su vida (1868-1951), algo anteriores y posteriores ${ }^{56}$, me hizo ver que tal visión no era válida para explicar la realidad, al menos en el período citado y en los lugares e instituciones en los que Hoyos llevó a cabo su labor: o sea, en un caso concreto (que puede extenderse también a Telesforo de Aranzadi y otros). Hoyos, por formación académica y configuración intelectual, era un naturalista, pero su visión de la antropología era integradora, acogiendo la antropología física y la etnología, como demuestra su contribución importante a ambas ramas. Se unían por tanto en él las dos vías paralelas a las que antes se aludió, que, por otro lado, él no veía como tales, utilizando y citando la investigación anterior sobre la cultura y el hombre hispanos siempre que le resultara válida y considerándose seguidor de autores pertenecientes a ambas supuestas tradiciones. En su trabajo «Notas para la historia de las ciencias antropológicas en España» (1912) se refleja la configuración holística de la antropología española a la que me he referido ${ }^{57}$.

El ejemplo de Hoyos, muestra, por tanto, que el análisis biográfico no sólo sirve en cuanto aportación de datos y conocimiento de tipo monográfico sobre un caso particular (que puede ser más o menos significativo e importante), sino que contribuye a generar y matizar hipótesis y problemas de orden más general. Puede llegar a ser, en ocasiones, el punto de vista adecuado para el enfoque de algunos de ellos, y el personalismo de nuestra historia científica nacional contribuye a incrementar notablemente su interés, haciéndolo idóneo, al menos en una etapa básica de la investigación histórica. A través de la historia personal de los científicos podemos entender y caracterizar mejor el tipo de antropología que se hizo en nuestro país en el pasado, que si recurrimos, por ejemplo, al desarrollo de escuelas y tendencias teóricas en el marco universitario, donde escasamente llegaríamos a encontrar algún reflejo de la disciplina.

" Joan PRAT i CARós, «El discurso antropológico y el discurso folklórico en el estado español: Un ensayo de caracterización», IV Congreso de Antropología (Alicante) (1987), 64 pp., s.p.

"Carmen Ortiz Garcia, Luis de Hoyos Sáinz y la antropología española (Madrid: CSIC, 1987).

` Ibid., pp. 476-489. 
Aunque podrían seguir exponiéndose otros muchos aspectos, para finalizar, se pueden enumerar, por una parte, algunos elementos metodológicos positivos contenidos en las biografías científicas: integración de contextos social, ideológico, académico, político, etc.; visión cualitativamente profunda de la personalidad intelectual y carácter de la obra del investigador; utilización de fuentes documentales precisas y originales. Por otra parte no deben olvidarse los condicionamientos negativos, como la posibilidad de incurrir en el particularismo y hacer, a través de ellas, una historia más externa que dirigida al desarrollo de los avances del conocimiento. Sin embargo, y teniéndolos en cuenta, hay que señalar que, de alguna manera, el enfoque biográfico es inevitable en la historia, de la ciencias o de cualquier otra obra humana, y que la escala cronológica básica en que se desenvuelve esta obra es el transcurrir de una vida.

\author{
CARMEN ORTIZ GARCÍA \\ C.S.I.C., Madrid
}

El artículo pretende resaltar la importancia de la perspectiva en la historia de la antropología española. De modo introductorio, se trata de la utilización de la biografía en la historia, la sociología y la etnología. A continuación, se analiza la presencia del enfoque biográfico en la historia de las ciencias y la metodología de trabajo en la realización de biografías de científicos. Se exponen los géneros biográficos más frecuentes en la historiografía antropológica en general y, finalmente, se remarca la pertinencia de los estudios biográficos para el caso español.

This paper emphatizes the importance of the biographical perspective in the history of Spanish anthropology. After an introduction about the use of biography in history, sociology and ethnology, the biographical point of view is analyzed in the history of sciences and the guidelines governing the writing of a scientist's life are given. The most frequent biographical genres in anthropological historiography are also stated, and finally the relevance of this kind of historical analysis is vindicated for the Spanish scholarship. 